\title{
Linking Glaciers on Earth to the Climate on Mars
}

\author{
Geophysicist Jack Holt explains how Earth's debris-covered glaciers can \\ teach us about the climate history of Mars.
}

By Rachel Berkowitz

A

s a student, Jack Holt had three loves: geology, exploring remote mountain regions, and aviation.

Now, as a geophysicist at the University of Arizona, he's merged those loves into his academic pursuits. Holt has tracked the history of Earth's magnetic field, which required visits to Death Valley in California, Baja California in Mexico, and the Big Island, Hawaii, and he ran an airborne field program to study the internal properties of glaciers, which took him to Antarctica. There, he used his postdoctoral experience in airborne radar sounding-a geophysical technique based on long-wave echo reflections-to map features buried beneath ice sheets.

When Holt learned that NASA planned to put similar radar

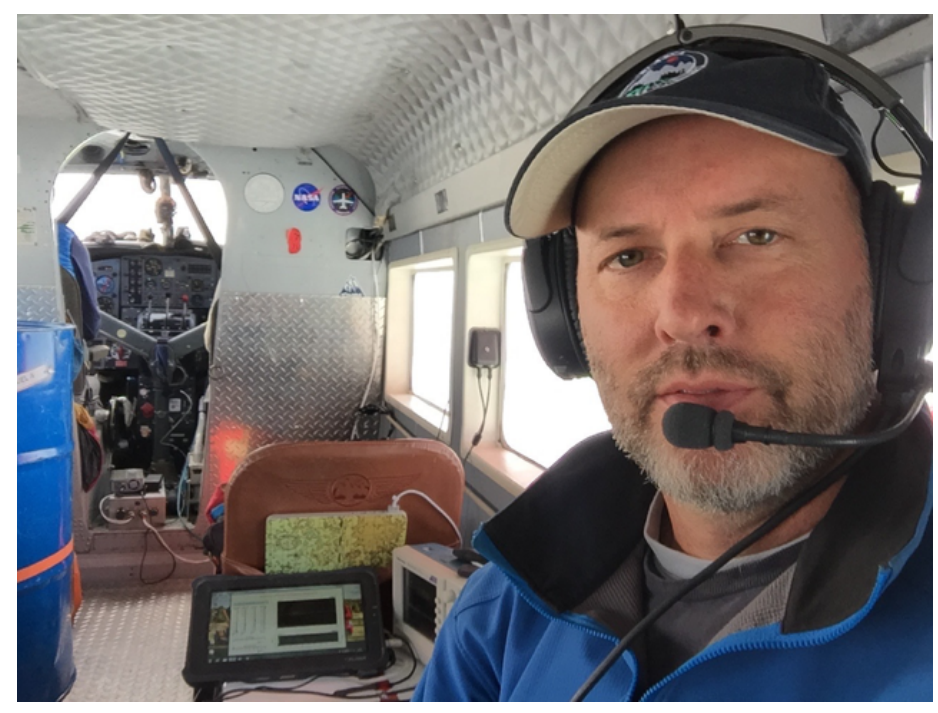

Credit: Jack Holt technology on the 2006 Mars Reconnaissance Orbiter, he applied to be part of the science team. (That spacecraft searched for signs of ice below the Martian surface.) Now he spends summers mapping debris-covered glaciers in Wyoming and Alaska to piece together the history of ice and climate on Mars. Physics spoke to Holt about the allure of glaciers and about what he hopes to learn about these icy bodies, both on Earth and on Mars.

All interviews are edited for brevity and clarity.

\section{What fascinates you about glaciers?}

Glaciers grow and shrink on timescales of a few months to a few years, which is short enough that we can witness how they change the features of a landscape almost in real time. That is a rare feat in geology, where landscape alterations typically take centuries. Glaciers also matter for climate change; I like working on problems that have relevance to our planet and to society.

\section{What drew you to studying glaciers on Mars?}

The 1976 images of Mars from NASA's Viking missions. The missions happened long before I started my research career, but they prompted questions about the origin of some of Mars' landforms that were still not fully answered when I embarked on my Ph.D. Most people interpreted the landforms as coming from debris flows, but a few thought they might be glaciers. Either way, the images suggested ice played a role, even though ice should be unstable in Mars' atmosphere at the latitudes where these are found, so glaciers didn't initially make sense. The Viking images show smooth, pancake-shaped areas sitting between rocky massifs, or groups of mountains, with indications of past flow. On Earth, these patterns are produced 


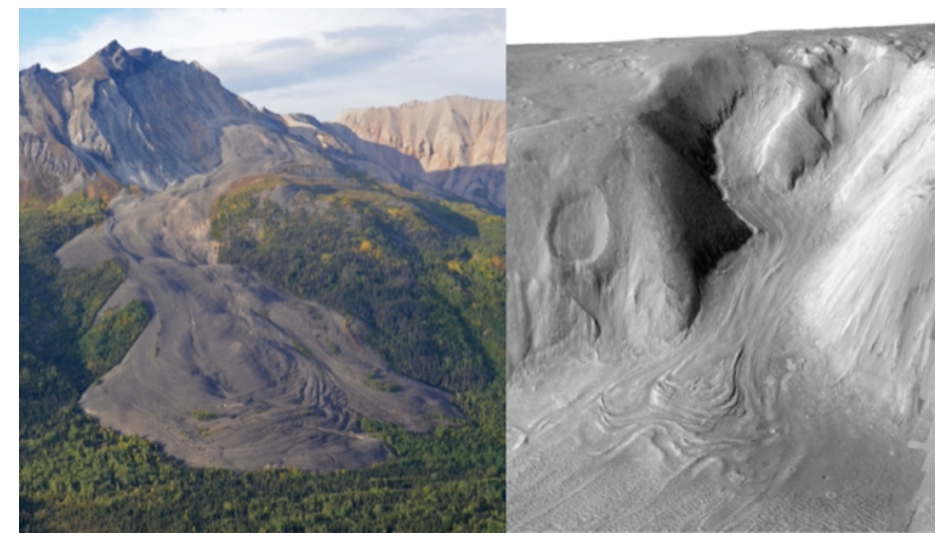

Features at Mars's mid-latitude regions (right) resemble those of the debris-covered Sourdough Peak rock glacier in Alaska (left). The similarities have led researchers to conclude that Mars, too, has debris-covered glaciers on its surface.

Credit: (Left) Eric Petersen; (Right) NASA/JPL/University of Arizona

by glaciers that carry rock and dust mixed with ice. One possibility was that the Mars images captured dust- and rock-covered glaciers that-like glaciers in the Dry Valleys of Antarctica-sit in valleys. But nobody was convinced at the time.

\section{And now?}

Now, opinions have changed. Radar images captured by the 2006 Mars Reconnaissance Orbiter are consistent with Mars having hundreds-of-meters-thick glaciers that are overlain with ten meters or less of rock and dust. Other geologists studying the images have concluded that the debris layer protects the ice from sublimating.

But we still have no idea how the glaciers first formed, whether Mars has had a single "ice age" or many, or if the glaciers contain a long-term record of Mars' climate.

\section{How do you plan to answer these questions?}

Before the Mars Reconnaissance Orbiter launched, I led an airborne radar study over the Dry Valleys of Antarctica. The initial plan to directly image a buried glacier didn't work, but I developed techniques that allowed us to better interpret the data, which turned out to be a requirement for studying glaciers on Mars.
Ideally, to directly see inside a Martian glacier, we would land a radar on Mars and then drag it across the planet's surface. That method works in Antarctica, where researchers have found that glaciers contain dipping layers that were laid down in different climate epochs. But unfortunately, it's not going to happen on Mars for a long time; it's just not a top priority.

\section{Is there evidence that layers exist in glaciers on Mars?} Yes. On Mars, we observe "transverse ridges" on the glaciers' surfaces, which on Earth are indicative that a glacier contains layers that intersect the surface.

Glaciers aren't made entirely from ice; sometimes they have a layered structure that alternates between ice and rock. For example, the glaciers I study in Wyoming are remnants from the last ice age and are covered with debris from nearby hillsides. The accumulating rock insulated the glaciers and stopped the ice from retreating. Ice and snow accumulated on top of this rock during a cold period, creating a snow-rock sandwich, and then more rock fell on top, and so on. This layered structure appears as horizontal ridges that span the length of the glacier's leading edge.

\section{How do you extrapolate measurements made on Earth to those on Mars?}

Using numerical models. I am currently developing one that links together the internal structure, morphology, and flow dynamics of Earth's glaciers. The plan is to input data from Mars into the model to infer the internal structure of its glaciers and link that to climate information.

\section{So, no results yet?}

We're a couple of years away from being able to apply the model in a solid way. My colleagues and I have found a climate signal using a different method, however. We used high-resolution imagery to look at the boulders that sit atop a sampling of Mars' glaciers. The images show distinct bands, each of which contains a different size of boulder, along the glacier's surface-suggesting that they were laid down at different times. These bands correspond to the ridges, which is what you'd expect to form through multiple climate cycles.

NASA recently landed the Perseverance rover on Mars. Will you learn anything from that about the planet's 


\section{glaciers?}

Sadly, no. Perseverance won't come close to Mars' glaciers. But we should learn something from the proposed Ice Mapper mission, which is targeted to launch in 2026. Ice Mapper will carry out radar measurements of ice across the planet. We're all looking forward to that.
Rachel Berkowitz is a Corresponding Editor for Physics based in Vancouver, Canada. 